\title{
Earthquake Damage Assessment for RC Structures Based on Fuzzy Sets
}

\author{
Haoxiang He, Maolin Cong, and Yongwei Lv \\ Beijing Key Lab of Earthquake Engineering and Structural Retrofit, Beijing University of Technology, Beijing 100124, China \\ Correspondence should be addressed to Haoxiang He; hhx7856@163.com
}

Received 3 August 2013; Revised 25 October 2013; Accepted 28 October 2013

Academic Editor: Anaxagoras Elenas

Copyright (C) 2013 Haoxiang He et al. This is an open access article distributed under the Creative Commons Attribution License, which permits unrestricted use, distribution, and reproduction in any medium, provided the original work is properly cited.

\begin{abstract}
A global damage index based on multiple linear force-deformation curves in pushover analysis is presented to evaluate the integrated damage of reinforced concrete structure. The modified coefficient is provided considering the cyclic load and hysteresis energy. The number of inelastic cycles and the coefficient of hysteresis energy concentration are also introduced as damage indices. Hence, multiple damage indices about displacement and energy for performance-based design are considered. The relation of multiple damage indices or factors and the fuzzy damage set is presented by comprehensive fuzzy evaluation; hence, a performancebased multiple fuzzy seismic damage-assessment method for reinforced concrete frame structures is established. The method can be accomplished based on pushover analysis, code spectrum, and capacity spectrum method. The fuzzy seismic damage-assessment method is verified through nonlinear analysis four different structures and the corresponding results and assessment conclusions are accurate.
\end{abstract}

\section{Introduction}

The reinforced concrete structure will inevitably be damaged and enter elastoplasticity deformation stage when it is subjected to strong ground motion. In order to determine the appropriate and economical selective intervention or rehabilitation strategy for an existing structure, it is necessary to assess accurately the actual resistance and the potential failure modes. It is also essential to carry out the damage assessment for a new designed building in order to verify that the performance and capacity meet the target specification of the seismic design guideline. Based on broad categories for advanced seismic design approaches, performance-based seismic design (PBSD) is at the forefront of earthquake engineering research [1-3]. One of the primary aspects of PBSD is the realistic characterization of seismic structural damage and its direct incorporation in the design or performance evaluation methodology. The damage assessment based on PBSD is to ensure that the structures achieve the expected targets for different performance requirements.

Structural ductility, storey drift, element and connection rotation, dissipated energy, and fatigue of the structure are the parameters considered for traditional damage assessment
[4]. Based on the fundamental parameters, various local and global damage indices have been proposed to evaluate reinforced concrete structures. Research on the global damage indices is essential because the integral damage assessment should be accurate and involve the damage properties of local elements. However, the global damage indices presented until now have the disadvantages such as limited convergence and not considering cumulative damage. In addition, many damage indices are obtained from pushover analysis and capacity spectrum method whose purpose is to evaluate structural performance under earthquake by overprinting seismic response spectrum curve and structural capacity curve [5]. A significant amount of research has shown that capacity spectrum method can simplify computation, consider the nonlinear performance of the structural elements and finally obtain effective results. Because capacity spectrum method has major simplifications, such as a multi-degree of freedom system being transformed into a single-degree of freedom system, nonlinear time-history analysis being replaced by pushover method, and accumulated dissipative effect not sufficiently considered, thus the evaluation is inexact in some cases, especially for irregular or complex structures. Hence, it is necessary to present a comprehensive 
method to combine multiple damage parameters and obtain more accurate results.

Moreover, the uncertainty always affects the modeling and evaluation of real physical phenomena with different intensity, the damage of structures in earthquake is a vague concept because there exists not explicit classification criterion to evaluate different damaged members and the structure with different damaged information. The values from different damage-assessment methods are also different and even distinct. Hence, the seismic damage assessment and the decision problem are very complex for large and complex structure, which needs the integration based on multiclass information, and the combination of different information is a valid method to reduce the deviation and the uncertainty. In the past decades several alternative mathematical approaches to deal with uncertainty have been developed and the main categories methods include fuzzy set theory, artificial neural networks, interval analysis, and convex modeling.

In classical set theory, the membership of elements in a set is assessed in binary terms according to a bivalent condition; that is, an element either belongs or does not belong to the set. By contrast, fuzzy set theory permits the gradual assessment of the membership of elements in a set [6]. This is described with the aid of a membership function valued in the real unit interval $[0,1]$. Fuzzy sets generalize classical sets, since the indicator functions of classical sets are special cases of the membership functions of fuzzy sets, if the latter only takes value 0 or 1 . The fuzzy logic and the fuzzy set provide a powerful tool to solve the uncertainty problem and describe the fuzzy characteristics of the target. Especially, fuzzy logic is fit for describing and processing the uncertain information from multiple sources. In recent years, the methods such as the fuzzy logic system, artificial neural networks, and other soft computing methods develop rapidly, which provides a solid theoretical basis for information fusion and system assessment.

In this paper, the multiple damage indices on displacement and energy for reinforced concrete structures are discussed and applied based on performance-based seismic design and the comprehensive evaluation method is proposed by applying fuzzy set theory. The relationship between the multiple damage factors and the fuzzy damage set is established and an effective and accurate seismic damageassessment method is presented.

\section{Damage-Assessment Index Based on Displacement and Energy}

2.1. Damage Index Based on Capacity Curve. The vulnerability of many existing structures may be due to structural weaknesses and low ductility. Common weaknesses in the structural system are due to incomplete load path; strength and stiffness discontinuities, vertical, horizontal and mass irregularities; weak column and strong beam, and eccentricities. Low ductility detailing is characterized as insufficient shear reinforcement, inadequate confinement, and insufficient anchorage length of the beam-reinforcement bars.

The state of damage of a component, a story, or the whole structure may be represented by an index. The damage index is used as an indicator to describe the state of the lateral load-carrying capacity and the reserve capacity of existing structures. Thus, the study on damage index and its availability is necessary.

Some damage indices are calculated for each component of the building (local damage index). The component damage indices may be integrated using a weighting procedure to provide the global damage index for the structure. These damage indices have been formulated using response parameters of the structure that are obtained through analytical evaluation of structural response. There are several techniques and approaches for damage analysis of structures, such as pushover analysis, nonlinear time history analysis, and vulnerability analysis. The typical response-based damage indices include ductility ratio, interstory drift, slope ratio, maximum drift, flexural damage ratio, low cycle fatigue, final softening index and Park-Ang index. The damage indices such as interstory drift and maximum drift, are fundamental and essential for representing the displacement or deformation.

Though various local and global damage indices were presented, the most acceptable damage index is the ParkAng damage index combining both ductility and cumulative hysteretic energy demand $[7,8]$ :

$$
D_{\mathrm{PA}}=\frac{\delta_{m}}{\delta_{u}}+\frac{\beta}{\delta_{u} F_{y}} \int d E_{h},
$$

where $\delta_{m}$ is the maximum experienced deformation, $\delta_{u}$ is the ultimate deformation of the element, $F_{y}$ is the yield strength of the element, $\int d E_{h}$ is the hysteretic energy absorbed by the element during the response history, and $\beta$ is the model constant, parameter, which was suggested to be 0.1 for nominal strength deterioration.

The Park-Ang damage index also has deficiencies even though many modified method were proposed [9-12]. A perfect damage index typically normalizes the damage on a scale of 0 to 1 , where zero represents undamaged state while unity represents the collapse state of the building. The maximum of the Park-Ang damage index is over 1 and nearly close to 2 in some cases. In addition, the Park-Ang damage index is not directly suitable for nonlinear static pushover analysis or normal capacity spectrum method because the cumulative damage does not occur in this case.

Based on pushover analysis, a stiffness damage index of the global frame was presented by Ghobarah et al. [4]:

$$
D_{k}=1-\frac{k_{F}}{k_{I}},
$$

where $k_{I}$ is the initial slope of the base shear-top deflection relationship resulting from the pushover analysis of the frame before subjecting it to the earthquake ground motion and $k_{F}$ is the initial slope of the same relationship but after subjecting the frame to the earthquake time history. The values of these damage indices range from zero to one depending on the amount of damage experienced.

Although the stiffness damage index has some advantages such as being concise and using pushover analysis twice 


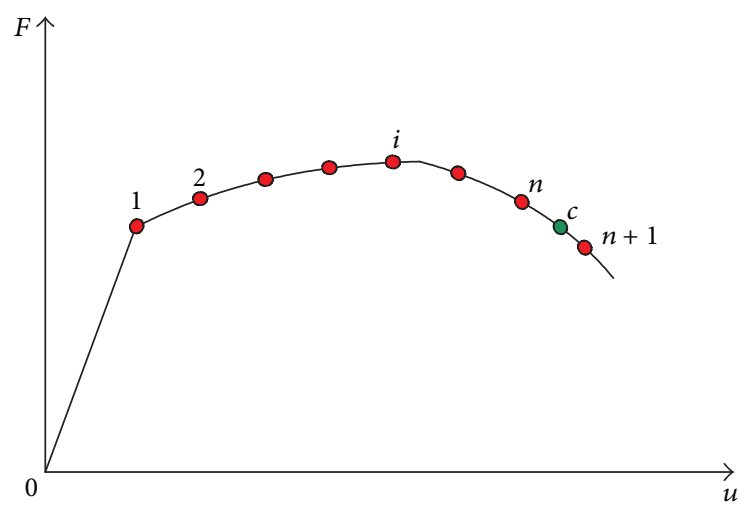

FIGURE 1: Multiple linear force-deformation curve.

without any other dynamic analysis, the limitation is also obvious. The damage evaluation is not accurate for moderate damage and collapse stage and the value may exceed 1 and the index is not obtained taking into account cumulative effect. In general, a new and comprehensive damage index needs to be proposed by combining the stiffness damage index and ParkAng damage index.

Referring to (2), a similar stiffness damage index is proposed as

$$
D_{c}=1-\frac{k_{c}}{k_{0}},
$$

where $k_{0}$ is the initial stiffness of elastic stage and $k_{c}$ is the current stiffness.

It is worth noticing that the damage index in (2) and (3) can also be transferred as the index presented by Dipasquale and Cakmak [5].

$$
D_{c}=1-\frac{T_{0}^{2}}{T_{c}^{2}},
$$

where $T_{0}^{2}$ is the initial fundamental period and $T_{c}^{2}$ is the current fundamental period. The equation above is suitable especially for damage assessment based on time-history analysis because the instantaneous fundamental period can be acquired conveniently.

According to (3), the relationship of current force $F_{c}$, the current displacement $u_{c}$ and the damage index are as follows

$$
F_{c}=k_{0}\left(1-D_{c}\right) u_{c} \text {. }
$$

Based on the form of (5) The typical skeleton curve or capacity curve of reinforced concrete structure behaves nonlinear or multiple linear, as shown Figure 1, and the current force between the $i$ th point and the $i+1$ th point can be expressed as

$$
\begin{aligned}
F_{c}= & k_{0} u_{1}+k_{1}\left(u_{2}-u_{1}\right)+k_{2}\left(u_{3}-u_{2}\right) \\
& +\cdots+k_{n-1}\left(u_{n}-u_{n-1}\right)+k_{n}\left(u_{c}-u_{n}\right),
\end{aligned}
$$

where $k_{i}=\left(F_{i+1}-F_{i}\right) /\left(u_{i+1}-u_{i}\right)$.
A general global damage index for capacity curve or skeleton curve is obtained by substituting to (6) in (5) with the following result

$$
D_{c}=1-\frac{\sum_{i=0}^{n-1} k_{i}\left(u_{i+1}-u_{i}\right)+k_{n}\left(u_{c}-u_{n}\right)}{k_{0} u_{c}} .
$$

Compared to (2), the general global damage index presented in this paper has some advantages as follows: (a) the damage index varies from 0 to 1 , rigorously, and has definite mechanical significance. (b) The damage index is calculated based on only once capacity curve that is, only one pushover analysis is carried out (c) the damage index is suitable for the capacity curve and the damage index of any displacement or any force can be obtained.

\subsection{Damage-Index Adjustment Considering Hysteretic Energy.} During strong earthquakes, the deformation capacity of structures is reduced due to the cumulative damage caused by cyclic load. However, as the deficiency of pushover analysis, the cumulative damage is not embodied sufficiently and the corresponding modified coefficient is essential. A research on equivalent (reduced) ductility factors has been proposed by Fajfar and the cumulative damage effect is taken into account [13].

The total structure can be simplified as an equivalent single-degree-of-freedom ideal elastoplastic system and the following relations are found or defined: $F_{y}=m \omega^{2} \delta_{y}, \mu_{u}=$ $\delta_{u} / \delta_{y}$, and $\mu_{m}=\delta_{m} / \delta_{y}$, where $F_{y}$ is the yield strength of the system, $m$ is the mass, $\omega$ is the natural frequency, $\delta_{y}$ is the yield displacement, and $\mu_{u}$ is the normal ductility. $\delta_{m}$ is the monotonic displacement or current displacement and $\mu_{m}$ is the monotonic ductility factor.

The parameter $\gamma$, which is a function of dissipated hysteretic energy, maximum displacement, and the natural frequency of the structural system, is introduced as follows:

$$
\gamma=\frac{\sqrt{E_{H} / m}}{\omega \delta_{m}}=\frac{1}{\mu_{u}} \sqrt{\frac{E_{H}}{m}},
$$

where $E_{h}$ is the total hysteretic energy. The transformation can be obtained as

$$
\frac{E_{H}}{F_{y} \delta_{y}}=\gamma^{2} \mu_{m}^{2} .
$$

Substituting to (8) in (1), the Park-Ang damage index is rewritten as

$$
D_{\mathrm{PA}}=\left(1+\beta \gamma^{2} \mu_{u}\right) \frac{\mu_{u}}{\mu_{m}} .
$$

Thus, the relationship between displacement ductility factor on cumulative damage in earthquake and the displacement ductility factor in monotonic load is as follows:

$$
\frac{\mu_{u}}{\mu_{m}}=\frac{D_{\mathrm{PA}}}{\left(1+\beta \gamma^{2} \mu_{u}\right)} .
$$

For normal structure, the ratio $\mu_{u} / \mu_{m}$ ranges from 0.65 to 0.85 . The result of (11) can also be applied to (7) in order to 


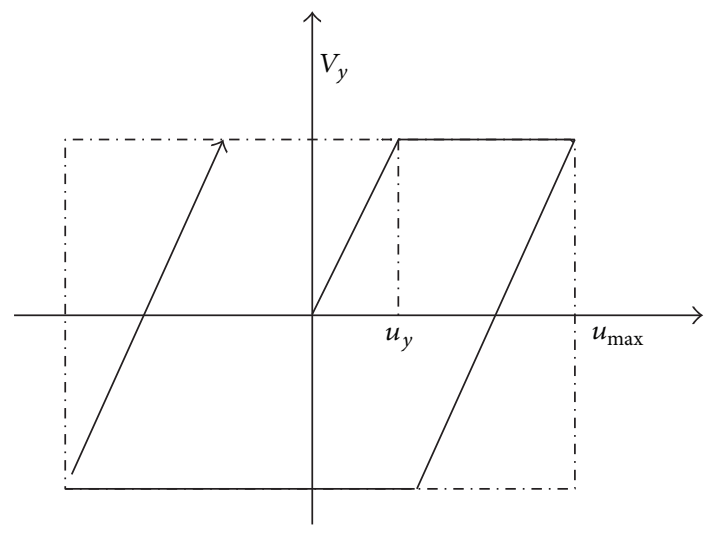

Figure 2: Idealized force-deformation behavior.

compute the damage index considering dissipated hysteretic energy. For the capacity point which means the crossover point of the capacity curve and the ductility spectrum curve, the corresponding displacement ductility is viewed as $\mu_{u}$, but the damage status in pushover analysis is related to the monotonic ductility $\mu_{m}$, so the displacement on the capacity point is advised to be amplified according to (11) in order to represent the actual damage.

2.3. Number of Inelastic Cycles. From another point of view, the cyclic demand spectrum for use in preliminary seismic assessment and design is necessary and Kunnath proposed a method based on estimating the number of equivalent cycles at a specified ductility [14]. The methodology is determined using well established relationships between seismic input energy and dissipated hysteretic energy.

If symmetric behavior is assumed, a commonly used idealization of the non-linear behavior is the elastic perfectlyplastic behavior shown in Figure 2. Assuming $V_{y}$ is the yield force, $u_{y}$ is the yield displacements and $u_{\max }$ is the peak displacements. The energy dissipated by the yielding element per cycle is

$$
E_{c}=4 V_{y} u_{\max }\left(1-\frac{1}{\mu_{c}}\right)=4 \alpha_{h} V_{y} u_{\max }
$$

where $\mu_{c}=u_{\max } / u_{y}$, is the cyclic displacement ductility factor and $\alpha_{h}$ is an energy shape factor that depends on both the ductility and the shape of the hysteresis loops. For a nondegrading system subjected to $N_{f}$ full cycles at the same ductility, the total energy dissipated is the product of $N_{f}$ and $E_{c}$, and the following expression between the number of inelastic cycles and dissipated hysteretic energy can be derived:

$$
N_{f}=\frac{E_{h}}{\left(4 \alpha_{h} \mu_{c} V_{y} u_{y}\right)} .
$$

Considering the dynamic characteristics and seismic design parameter, the number of inelastic cycles can also be rewritten as

$$
N_{f}=\left(\frac{r_{h I} E_{I}}{m}\right) \frac{\pi^{2}}{\alpha_{h} \mu_{c}}\left(\frac{R_{\mu}}{T S_{a}}\right)^{2}=\left(\frac{r_{h I} v_{e}^{2}}{2}\right) \frac{\pi^{2}}{\alpha_{h} \mu_{c}}\left(\frac{R_{\mu}}{T S_{a}}\right)^{2},
$$

where $r_{h I}=1.13\left(\mu_{c}-1\right)^{0.82} / \mu_{c}$ is the ratio of hysteresis energy to the total input energy $E_{I}, R_{\mu}$ is the force-reduction factor and the following expression is used

$$
\begin{gathered}
R_{\mu}= \begin{cases}\frac{\left(\mu_{c}-1\right) T}{T_{0}}+1, & T \leq T_{0}, \\
\mu_{c}, & T>T_{0},\end{cases} \\
T_{0}=0.65 T_{g}\left(\mu_{c}\right)^{0.3},
\end{gathered}
$$

where $T$ is fundamental period and $T_{g}$ is the characteristic period.

$S_{a}$ is the design spectral acceleration; $v_{e}$ is the equivalent input energy velocity, which is equal to the Fourier amplitude spectrum of the ground acceleration, and the typical expression is

$$
\begin{gathered}
v_{e}=\left\{\begin{array}{lc}
v_{e}^{*}\left(\frac{2 T}{T_{g}}-\left[\frac{T}{T_{g}}\right]^{2}\right), & T \leq T_{g}, \\
v_{e}^{*}\left[\frac{T}{T_{g}}\right]^{-\lambda}, & T>T_{g},
\end{array}\right. \\
v_{e}^{*}=\frac{\ddot{x}_{g \max }}{4 \dot{x}_{g \max }} \sqrt{\frac{\lambda+0.5}{2 \lambda+2} t_{d} T_{g}}=0.22 \pi \sqrt{\frac{t_{d}}{T_{g}},}
\end{gathered}
$$

where $v_{e}^{*}$ is the peak amplification factor for the input energy spectrum, $t_{d}$ is the duration for the strong motion phase of the ground motion, and $\lambda$ is a parameter that characterizes the spectral shape of the input energy spectrum for periods longer than the predominant period of the ground motion.

It is demonstrated that the force-deformation characteristics of the system, the ductility-based force-reduction factor $R_{\mu}$, and the ground motion characteristics play a significant role in the cyclic demand imposed on a structure during severe earthquakes.

2.4. Coefficient of Hysteresis Energy Concentration. The new and effective global damage indices are described as above. Furthermore, the deformation and hysteresis energy of the special weak stories is important because the structural weakest-part would suffer from severe damages due to its inability to withstand the different types of loads (lateral, vertical and moments) produced by the ground motion [15, 16]. The failure of the weak story can reduce the structural performance though other floors are merely in moderate damage stage. For irregular structures and complex structures, the damage assessment on weak floors is necessary besides the normal analysis carried out.

The coefficient of story yield shear is defined as $\xi_{y}=$ $V_{y} / V_{e}$, where $V_{y}$ is the yield shear force of a story in the 
TABLE 1: Statistical values for story yield shear and hysteresis energy concentration.

\begin{tabular}{lccc}
\hline Structure & \multicolumn{3}{c}{ Parameter } \\
& $a_{n}$ & $b_{n}$ & $c_{n}$ \\
\hline 5-story & -8.50 & 6.50 & 3.00 \\
12-story & -10.0 & 7.02 & 4.00 \\
20-story & -12.0 & 8.06 & 5.00 \\
\hline
\end{tabular}

structure, and $V_{e}$ is the elastic shear force of the story, that is, the shear force for the same deformation if the structure is elastic. The coefficients of story yield shear in each story are equivalent for a regular structure; otherwise the values diverge. The story belongs to a weak story if the coefficient of story yield shear exceeds the threshold value.

The input energy of a multidegree-of-freedom system sustained to an earthquake depends on the structural mass and initial stiffness, in spite of the yield strength value. The story yield first almost is the story that the elastic displacement is the largest and the inelastic interstory drift is also greater than others. The hysteresis energy of the weak story is also greater than that of other stories.

Based on a large number of nonlinear time-history analyses considering various ground motions, fundamental periods, coefficients of story yield shear, and different number of weak stories, the fitting equation of the coefficient of story yield shear and the coefficient of hysteresis energy concentration is as follows:

$$
\eta_{n}=-a_{n} \xi_{y}^{2}+b_{n} \xi_{y}+c_{n}
$$

where $n$ is the story number of structure and $a_{n}, b_{n}$, and $c_{n}$ are the parameters varying with $n$. The statistical values for the structures with different stories are given in Table 1.

The coefficient of story yield shear in each story used to be over 0.3 even if the normal structures are subjected to severe earthquake. Thus the coefficient of hysteresis energy concentration generally decrease when the coefficient of story yield shear increases. Hence, the energy distribution can be obtained through calculating the coefficient of hysteresis energy and measuring the damage-degree by energy is achieved.

2.5. Damage Grade and Damage Target. According to the discussion above and the damage indices presented, the global damage index and corresponding adjustment are viewed as an accurate damage-evaluation approach and the number of inelastic cycles can fully embody the integral hysteresis. These two damage indices represent the integral damage states in a reinforced concrete structure. On the other hand, the maximum interstory drift and the coefficient of hysteresis energy concentration can represent the local damage details. Hence, all the four damage indices are advised to be combined and used in damage assessment generally.

Taking into account the damage degree description in Table 2 and the empirical values from nonlinear analysis, the damage degree and the limit values for different damage indices are listed in Table 3.

\section{Damage-Assessment Based on Fuzzy Set}

3.1. Damage Assessment Model Based on Fuzzy Set. In many practical cases, the structural damage is a fuzzy and vague state because there are no obvious and clear grading marks in the actual status; furthermore, the results of damage assessment based on different damage indices disagree in special cases [17]. These problems may occur when data in Table 3 is used without identification and consideration. Thus, this is more scientific and objective for structural damage according to fuzzy set theory by introducing the concept of fuzzy subset and fuzzy membership [18-21]. In classical set theory, the membership of elements in a set is assessed in binary terms according to a bivalent condition; that is, an element either belongs or does not belong to the set. By contrast, fuzzy set theory permits the gradual assessment of the membership of elements in a set; this is described with the aid of a membership function valued in the real unit interval $[0,1]$. Fuzzy sets generalize classical sets, since the indicator functions of classical sets are special cases of the membership functions of fuzzy sets, if the latter only take the value 0 or 1. The fuzzy decision fusion method realizes the integration fusion by using fuzzy transform principle and maximum membership principle and considering the various factors relevant to the evaluation objects. In the evaluation process, the factors constitute the factor set as $U=\left\{U_{1}, U_{2}, \ldots, U_{m}\right\}$ according to different extent and the decision is expressed as the decision set as $V=\left\{V_{1}, V_{2}, \ldots, V_{n}\right\}$.

First, the single factor decision is made for the single factor $u_{i}(i=1,2, \ldots, m)$ in the factor set $U$, then the membership degree $r_{i j}$ in the decision degree $v_{j}(j=1,2, \ldots, n)$ is determined according to $u_{i}$. Thus, the single factor decision set for the factor $u_{i}$ is obtained as $r_{i}=\left\{r_{i 1}, r_{i 2}, \ldots, r_{i n}\right\}$, which is the fuzzy subset of the decision set. Hence, considering all the $m$ factors, the general fuzzy decision matrix is constructed as

$$
R=\left\{\begin{array}{c}
r_{1} \\
\vdots \\
r_{m}
\end{array}\right\}=\left[\begin{array}{ccc}
r_{11} & \cdots & r_{1 n} \\
\vdots & \ddots & \vdots \\
r_{m 1} & \cdots & r_{m n}
\end{array}\right]
$$

where $R$ is the fuzzy relationship between factor domain and decision domain and $r_{i j}$ is the membership degree. Multi-factor decision should consider the weighted grade for each factor in the fusion process. The fuzzy subset $A=$ $\left\{a_{1}, a_{2}, \ldots, a_{m}\right\}$ is the weighted set in factor domain $U$, where $a_{i}\left(a \leq a_{i} \leq 1\right)$ is the weight value of the single factor $u_{i}$ in the total decision. When $A$ and $R$ are determined, the fusion is carried out by fuzzy transformation $B=A \circ R, B$ is equivalent fuzzy subset in the evaluation set $V$, the element $b_{j}(j=1,2, \ldots, n)$ is the fusion result for grade $v_{j}$, and $\circ$ is the fuzzy synthesis operator.

The membership function is the normal distribution function $\mu(x)=e^{-((x-k) / t)^{2}}$, where the parameters $k$ and $t$ could be determined according to the following principles: (1) the membership value is 1 when the factor is equal to the mean value, (2) the membership value of the top and bottom limitations in the universe of a fuzzy set can be adjusted to 
TABle 2: Damage-degree description.

\begin{tabular}{|c|c|c|c|}
\hline Damage degree & Global appearance & Column & Beam \\
\hline Slight & Sporadic occurrence of cracking & $\begin{array}{l}\text { Very fine cracks (less than } \\
0.1 \mathrm{~mm} \text { ) }\end{array}$ & $\begin{array}{l}\text { Very fine cracks (less than } \\
0.1 \mathrm{~mm})\end{array}$ \\
\hline Minor & $\begin{array}{l}\text { Minor cracks; partial crushing of } \\
\text { concrete in columns }\end{array}$ & Visible cracks ( 0.1 to $0.2 \mathrm{~mm}$ ) & $\begin{array}{l}\text { Visible shear cracks (near } \\
\text { support) or tension cracks (at } \\
\text { bottom) }(0.1 \text { to } 0.2 \mathrm{~mm})\end{array}$ \\
\hline Moderate & $\begin{array}{l}\text { Extensive large cracks; spalling of } \\
\text { concrete in weaker elements }\end{array}$ & $\begin{array}{l}\text { Major portion of outer layer of } \\
\text { concrete is spalled but core is } \\
\text { intact except for hairline cracks } \\
(0.2 \text { to } 0.5 \mathrm{~mm})\end{array}$ & $\begin{array}{l}\text { Major portion of outer layer of } \\
\text { concrete is spalled but core is } \\
\text { intact except for hairline cracks } \\
(0.2 \text { to } 0.5 \mathrm{~mm})\end{array}$ \\
\hline Severe & $\begin{array}{l}\text { Extensive crashing of concrete; } \\
\text { disclosure of buckled } \\
\text { reinforcement }\end{array}$ & $\begin{array}{l}\text { Diagonal/torsional cracks in } \\
\text { concrete core ( } 0.5 \text { to } 3 \mathrm{~mm}) \text {, } \\
\text { opening of tie bars, and bucking } \\
\text { of longitudinal bars }\end{array}$ & $\begin{array}{l}\text { Reinforcement and concrete } \\
\text { bond is broken, there are cracks } \\
\text { in the core concrete ( } 0.5 \text { to } \\
3 \mathrm{~mm} \text { ), and shear tie bar have } \\
\text { failed }\end{array}$ \\
\hline Collapse & $\begin{array}{l}\text { Partial or total collapse of } \\
\text { building }\end{array}$ & $\begin{array}{l}\text { Crushing of core concrete at } \\
\text { joints and relative movement } \\
\text { with respect to slab and other } \\
\text { columns (cracks }>3 \mathrm{~mm})\end{array}$ & $\begin{array}{l}\text { Crushing of concrete at supports } \\
\text { and excessive deflection }\end{array}$ \\
\hline
\end{tabular}

TABLE 3: Damage degree and the limit value for different damage indices.

\begin{tabular}{lcccc}
\hline $\begin{array}{l}\text { Seismic fortification } \\
\text { level }\end{array}$ & Frequent earthquake & \multicolumn{2}{c}{ Moderate earthquake } & Rare earthquake \\
\hline $\begin{array}{l}\text { Damage degree } \\
\text { Global damage index }\end{array}$ & Intact & Minor damage & Moderate damage & Severe damage \\
$\begin{array}{l}\text { Number of inelastic } \\
\text { cycles }\end{array}$ & $0 \sim 0.10$ & $0.10 \sim 0.30$ & $0.30 \sim 0.65$ & $0.65 \sim 0.85$ \\
Maximum interstory & - & - & $10 \sim 20$ & $4 \sim 10$ \\
drift & $0 \sim 1 / 450$ & $1 / 450 \sim 1 / 300$ & $1 / 300 \sim 1 / 150$ & $1 / 150 \sim 1 / 50$ \\
$\begin{array}{l}\text { Coefficient of } \\
\text { hysteresis energy }\end{array}$ & $1.0 \sim 2.073+0.046 n$ & $0.046 n \sim 2.854+$ & $0.084 n \sim 3.346+$ & $0.113 n \sim 3.554+$ \\
concentration & & $0.084 n$ & $0.113 n$ & $0.132 n$ \\
\hline
\end{tabular}

1, and (3) the membership value on the boundary in the universe of a fuzzy set is 0.5 .

\subsection{Damage Assessment Based on Fuzzy Set. Considering} various damage indices for reinforced concrete structures, the damage assessment should use one or multilevel fuzzy fusion. According to the importance and the accuracy of each index, the factor fuzzy vector can be determined by the expert experience or analytic hierarchy process, and the membership function is Gaussian model.

Taking a reinforced concrete structure as an example, the global damage index, the number of inelastic cycles, the maximum interstory drift, and the coefficient of hysteresis energy concentration are the main parameters that accurately reflect the structural damage information and they are easy to obtain. Therefore, these parameters are selected in for fuzzy decision.

The weighted values for the parameters can be determined according to the experts grading method or the analytic hierarchy process (AHP). The AHP is a theory of measurement through pairwise comparisons and relies on the judgments of experts to derive priority scales [22].
Considering the importance and calculation accuracy of the grade index about damage state in the factor domain and the result from AHP, the weight value matrix of the damage index is $\mathbf{A}=[0.4,0.25,0.2,0.15]$. The structural damage grade is divided into 5 grades: intact, minor damage, moderate damage, severe damage, and collapse. The damage assessment and grade index are shown in Table 1.

After the fuzzy damage subset is determined, the membership value for the specific damage status in each damage grade can be calculated. In order to meet the requirements of performance-based design, the quantitative description of damage degree is needed. To highlight the dominance hierarchy, the general fuzzy damage index for decisionmaking is suggested as

$$
\mathrm{GFD}=\frac{\sum_{i=1}^{4} b_{i}^{k} D a_{i}}{\sum_{i=1}^{4} b_{i}^{k}}
$$

where $b_{i}$ is the membership value of the $i$-level damage, $D a_{i}$ is the median value in the $i$-level damage and $K$ is the comprehensive adjustment index, where it is recommended that $k$ is taken as 2 . 
TABLE 4: The results of performance indexes of example structures.

\begin{tabular}{lccccccc}
\hline Parameter & $\begin{array}{c}\text { Global damage } \\
\text { index }\end{array}$ & $\begin{array}{c}\text { Maximum } \\
\text { interstory drift }\end{array}$ & $\begin{array}{c}\text { Number of } \\
\text { inelastic cycles }\end{array}$ & $\begin{array}{c}\text { Coefficient of } \\
\text { hysteresis } \\
\text { energy } \\
\text { concentration }\end{array}$ & $\begin{array}{c}\text { Equivalent } \\
\text { yield } \\
\text { displacement } \\
\text { (m) }\end{array}$ & $\begin{array}{c}\text { Equivalent } \\
\text { ductility factor }\end{array}$ & $\begin{array}{c}\text { Equivalent } \\
\text { period (s) }\end{array}$ \\
\hline Frame 1 & 0.783 & 0.019 & 10.564 & 4.201 & 0.183 & 2.743 & 0.411 \\
Frame 2 & 0.762 & 0.025 & 3.338 & 5.334 & 0.205 & 2.126 & 1.968 \\
Frame 3 & 0.861 & 0.043 & 2.278 & 4.616 & 0.229 & 2.741 & 1.191 \\
Frame 4 & 0.726 & 0.017 & 6.073 & 4.238 & 0.131 & 2.774 & 0.752 \\
\hline
\end{tabular}

3.3. Damage-Assessment Procedure. In summary, the procedure of damage assessment based on fuzzy set is as follows:

(1) Determine the decision set as $V=\left\{V_{1}, V_{2}, \ldots, V_{n}\right\}$ in order to describe the different damage grade and the get the equivalent fuzzy subset $B$ in the evaluation set $V$.

(2) Select the factor domain as $U=\left\{U_{1}, U_{2}, \ldots, U_{m}\right\}$; then the damage factors are determined. The corresponding fuzzy subset $A=\left\{a_{1}, a_{2}, \ldots, a_{m}\right\}$ is also established.

(3) The nonlinear response is obtained by pushover analysis and capacity spectrum method and the damage indices are calculated.

(4) The membership function is calculated and the fuzzy relationship matrix is obtained.

(5) The equivalent fuzzy subset in the evaluation set $V$ is calculated by $B=A \circ R$.

(6) Compute the general fuzzy damage index (GFD) and determine the damage degree of the structure.

\section{Case Studies}

In order to verify the damage-assessment method based on fuzzy set, four three-dimensional reinforced concrete frames sustained to strong earthquake are selected to be analyzed by pushover analysis and nonlinear dynamic time history analysis using the three-dimensional nonlinear program CANNY [23]. These 4 structures are as follows: 5-story regular frame, 15-story regular frame, 9-story eccentric frame and 4-story partially symmetric frame, as shown in Figure 3 . The concrete compressive strength of the columns is $4 \times 10^{7} \mathrm{KN} / \mathrm{m}^{2}$, the compressive strength of the beams is $3 \times 10^{7} \mathrm{KN} / \mathrm{m}^{2}$, the yield strength of the main steel bars is $2.35 \times 10^{8} \mathrm{KN} / \mathrm{m}^{2}$, the reinforcement ratio of the columns and the beams are $2.2 \%$ and $1.8 \%$, respectively. According to the corresponding design demand, the dead loads and live loads in all the structures are $1.0 \mathrm{KN} / \mathrm{m}^{2}$ and $2.0 \mathrm{KN} / \mathrm{m}^{2}$ respectively, and the loads are transformed as node force in the finite element models. The seismic fortification intensity is 8 and the field type is medium soil.

The lateral load distribution of pushover analysis is adopted as the forms based on the stiffness distribution of each story. The capacity curves of the frames are obtained based on the capacity spectrum method. For the capacity spectrum method, an equivalent single-degree-of-freedom (ESDOF) system is a simplistic representation of the actual MDOF model, based on properties of the real structure; a bilinear idealization of the pushover curve can be obtained based on the principle of equality of energy.

For the time-history analysis, each group of waves has two orthogonal horizontal components and one vertical component, the three peak accelerations of each group are adjusted into $4.0 \mathrm{~m} / \mathrm{s}^{2}, 3.4 \mathrm{~m} / \mathrm{s}^{2}$ and $2.6 \mathrm{~m} / \mathrm{s}^{2}$, respectively, and the duration is 15 seconds.

Taking Frame 1 and Frame 3 as an example, the capacity curves and demand curves are shown in Figures 4 and 5 and the global damage curves are in Figures 6 and 7 shown respectively. In the figures, the global damage index on the capacity point is adjusted according to (11). The performance indices are calculated based on (7), (11), (14), and (17). The results are listed in Table 4. Damage assessment based on fuzzy set is carried out and the membership function is established according to the method previously described and specified index in Table 3. For example, the membership function of the global damage index is shown in Figure 8.

For frame 1, the fuzzy relation matrix is calculated according to (17) and, combined with the weight value matrix, the fuzzy damage vector is

$$
\begin{aligned}
B_{1}= & A \cdot R_{1}=[0.4,0.25,0.20,0.15] \\
& \times\left[\begin{array}{ccccc}
0 & 0 & 0.116 & 0.926 & 0.236 \\
0 & 0 & 0.472 & 0.551 & 0.015 \\
0 & 0 & 0 & 0.618 & 0.447 \\
0 & 0 & 0.081 & 0.565 & 0.451
\end{array}\right] \\
= & {[0,0,0.177,0.716,0.255] . }
\end{aligned}
$$

Frame 1 is identified as the structure with severe damage according to the fuzzy damage vector, then collapse and finally moderate damage. The first story is weak story according to the results on interstory drift. Equation (4) is applied as the average damage index for frame 1 in seismic timehistory analysis, the value is 0.776 , and the damage degree and locations are similar to the results of capacity spectrum analysis. The general fuzzy damage index (GFD) is 0.755 and the final assessment value quantized the damage status accurately. 


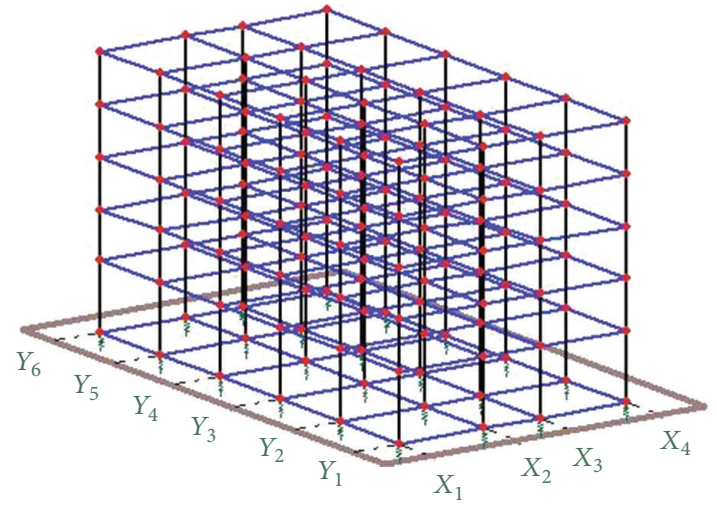

(a) 5-story regular frame

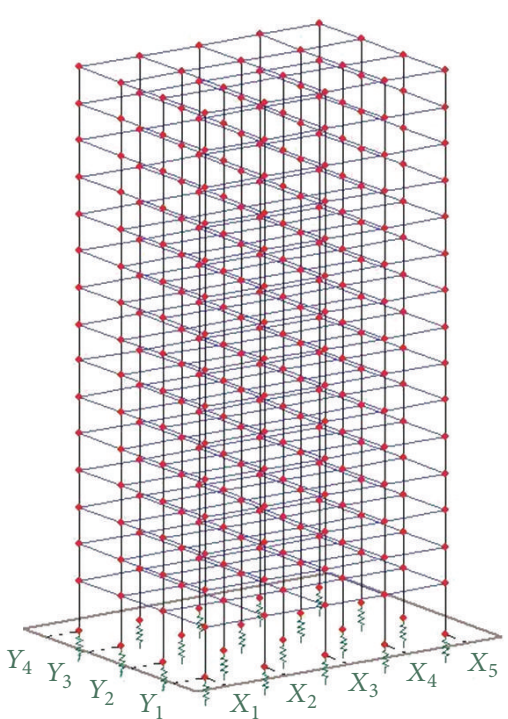

(b) 15-story regular frame

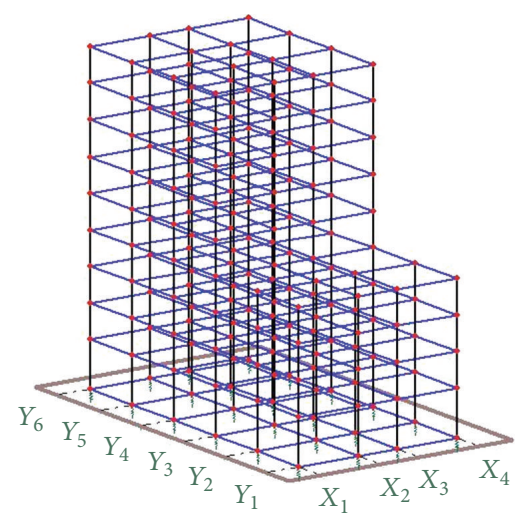

(c) 9-story eccentric frame

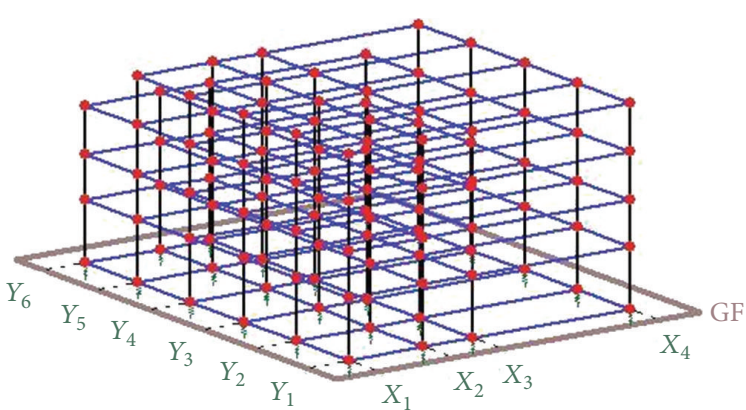

(d) 4-story partial symmetric frame

FIGURE 3: Side elevation of the reinforced concrete frames.

For frame 3, the fuzzy damage vector is

$$
\begin{aligned}
B_{3}= & A \cdot R_{3}=[0.4,0.25,0.20,0.15] \\
& \times\left[\begin{array}{ccccc}
0 & 0 & 0.034 & 0.425 & 0.552 \\
0 & 0 & 0.011 & 0.172 & 0.761 \\
0 & 0 & 0 & 0 & 1.000 \\
0 & 0 & 0 & 0 & 1.000
\end{array}\right] \\
= & {[0,0,0.016,0.213,0.761] . }
\end{aligned}
$$

Frame 3 is identified as the structure collapse after earthquake. The top story and the story with irregular stiffness are weak stories according to the results on the interstory drift. The average damage index according to (4) for seismic timehistory analysis is 0.856 . The general fuzzy damage index (GFD) is 0.858 and the final assessment value is similar to the damage information from the time-history analysis for strong earthquakes.

The important performance results and the fuzzy damage vectors of all the four frames are shown in Table 3 and Figure 9. It is evident that the end deformation of the beam and column in frame 2 and frame 3 is obvious, the weak stories are in failure, and the whole performance is deficient and will collapse in strong earthquakes, so the maintenance and retrofitting should be carried out. The damage of frame 1 and frame 4 are both severe but the structures still have the capacity and the performance requirements are met. It is obvious that the seismic damage-assessment method based on fuzzy sets is accurate and effective.

\section{Conclusion}

The damage index is the necessary basis of damage assessment for reinforced concrete structures. Both the global damage index which represents the integrated performance and the local damage index which highlight the damage details are discussed and presented. The response parameters based on displacement and hysteresis energy are all vital especially for the structures subject to earthquake, and the analysis method is suitable for performance-based seismic design and assessment. Though some damage indices such as Park-Ang damage index, are comprehensive and acceptable for normal 


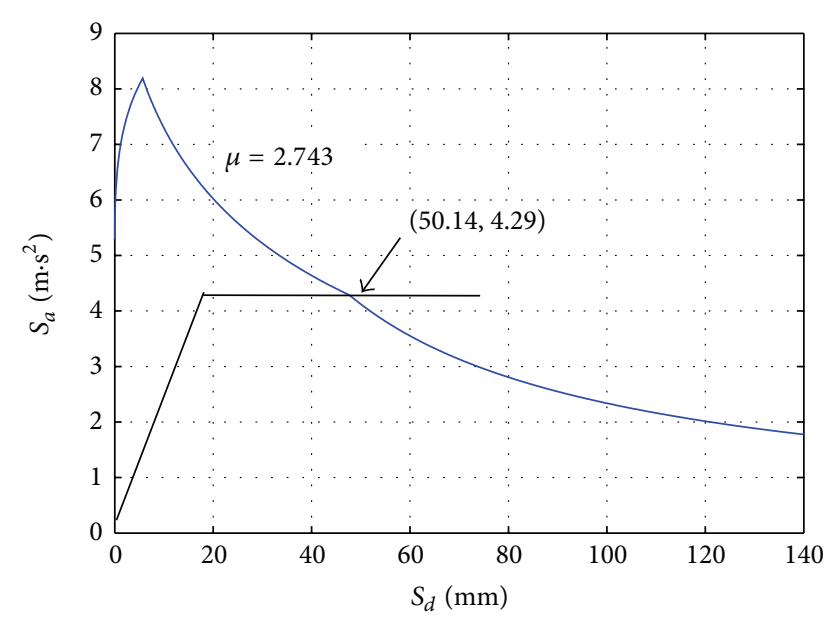

FIGURE 4: Capacity spectrum curve of frame 1.

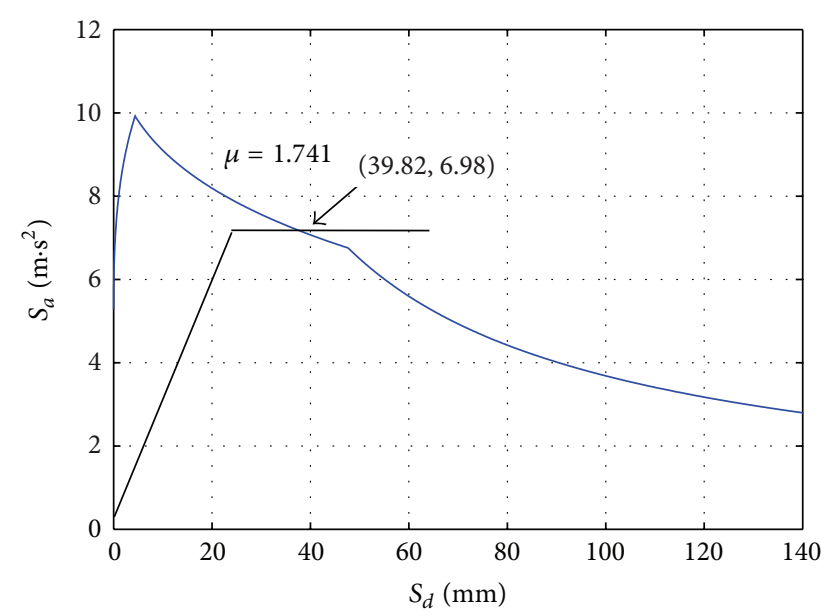

FIGURE 5: Capacity spectrum curve of frame 3.

damage assessment, it is unfortunate that these indices do not converge to unity and are unsuitable for pushover analysis if used directly. A global damage index based on multiple linear force-deformation curves in pushover analysis is presented to evaluate the integrate damage of reinforced concrete structure. The modified coefficient is provided considering the cyclic load and hysteresis energy. The number of inelastic cycles is introduced for the consideration of cyclic loads and hysteresis energy. The coefficient of hysteresis energy concentration is presented as a damage index which reflects the property and failure of the weak story. Thus, the global damage index, the number of inelastic cycles, the maximum interstory drift, and the coefficient of hysteresis energy concentration are all used as the damage indices of damage assessment.

In order to harmonize the different effects and weights, and reduce the uncertainty in the damage assessment, the fuzzy set theory is introduced, and the factor domain, the decision set, the fuzzy subset and the membership function are presented. The relation between the multiple damage

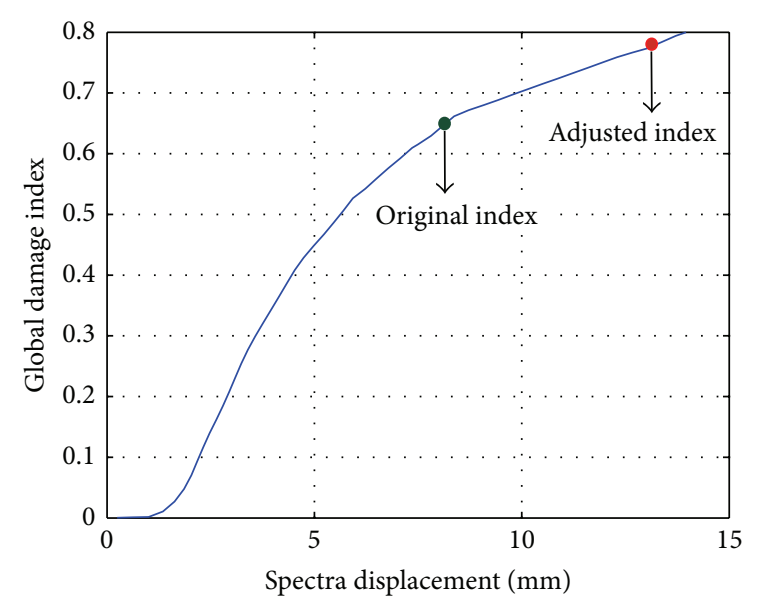

Figure 6: Curves of global damage index of frame 1.

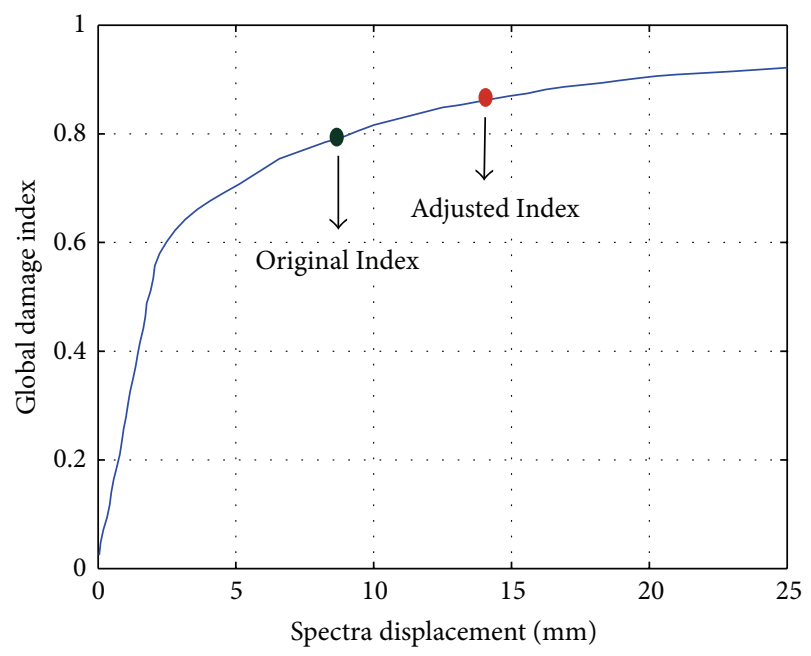

FIgURE 7: Curves of global damage index of frame 3.

indices or factors and the fuzzy damage set is established by comprehensive fuzzy evaluation based on fuzzy mathematics. The fuzzy seismic damage-assessment method is verified through nonlinear analysis for four different structures and the corresponding results and assessment conclusions are accurate, especially when compared with the responses from nonlinear time-history analysis.

The performance-based fuzzy seismic damage-assessment method presented in this paper can be improved and developed in some aspects such as determining the weight values by analytic hierarchy process (AHP) method and considering the multiple dimensional ground motion and the torsional effect in the irregular structures. Furthermore, the performance-based assessment including the foundation and the nonstructural components can also be established based on fuzzy evaluation system. 


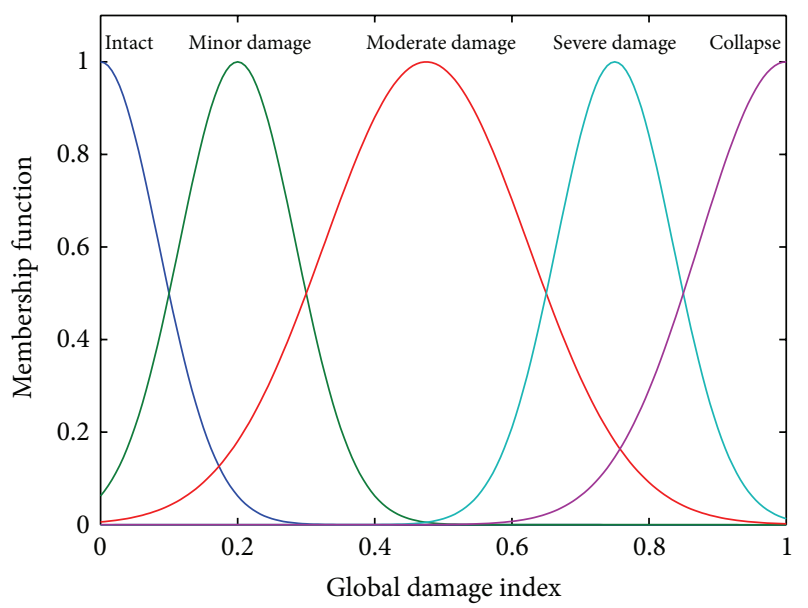

Figure 8: Membership grade of the global damage index.
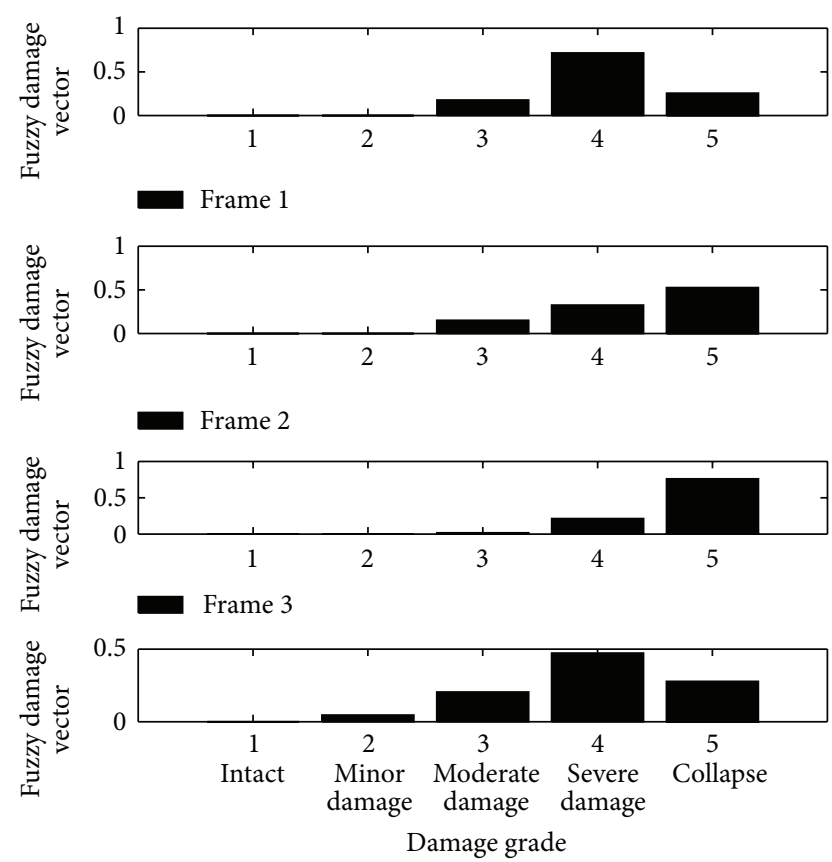

Frame 4

FIGURE 9: Damage grade for different frames.

\section{Acknowledgments}

This work is partially supported by Natural Science Foundation of China under Grant nos. 51108009 and 50878010, Foundation of the Ministry of Education of China for Outstanding Young Teachers in University under Grant no. 20111103120022, and Foundation of Beijing Key Lab of Earthquake Engineering and Structural Retrofit under Grant no. 2013TS02.

\section{References}

[1] SEAOC, Vision 2000: Performance Based Seismic Engineering of Buildings. Sacramento (CA, USA), Structural Engineers Association of California, 1995.
[2] A. Ghobarah, "Performance-based design in earthquake engineering: state of development," Engineering Structures, vol. 23, no. 8, pp. 878-884, 2001.

[3] M. J. N. Priestley, G. M. Calvi, and M. J. Kowalsky, Displacement Based Seismic Design of Structures, IUSS Press, Pavia, Italy, 2007.

[4] A. Ghobarah, H. Abou-Elfath, and A. Biddah, "Response based damage assessment of structures," Earthquake Engineering \& Structural Dynamics, vol. 28, no. 1, pp. 29-104, 1999.

[5] E. Dipasquale and A. S. Cakmak, "On the relation between local and global damage indices," Technical Report NCEER-89-0034, State University of New York at Buffalo, 1989.

[6] P. Fajfar, "Capacity spectrum method based on inelastic demand spectra," Earthquake Engineering \& Structural Dynamics, vol. 28, no. 5, pp. 979-993, 1999.

[7] L. A. Zadeh, "Fuzzy sets," Information and Control, vol. 8, no. 3, pp. 338-353, 1965.

[8] Y. J. Park, A. H. S. Ang, and Y. K. Wen, "Seismic damage analysis and damage limiting design of R.C. buildings," Structural Research Serial Report UILU-ENG-84-2007, University of Illinois at Urbana-Champaign, Urbana, Ill, USA, 1984.

[9] Y.-J. Park and A. H.-S. Ang, "Mechanistic seismic damage model for reinforced concrete," Journal of Structural Engineering, vol. 111, no. 4, pp. 722-739, 1985.

[10] D. Datta and S. Ghosh, "Uniform hazard spectra based on ParkAng damage index," Journal of Earthquake and Tsunami, vol. 2, no. 3, pp. 241-258, 2008.

[11] S. Ghosh, D. Datta, and A. A. Katakdhond, "Estimation of the Park-Ang damage index for planar multi-storey frames using equivalent single-degree systems," Engineering Structures, vol. 33, no. 9, pp. 2509-2524, 2011.

[12] A. Massumi and E. Moshtagh, "A new damage index for RC buildings based on variations of nonlinear fundamental period," The Structural Design of Tall and Special Buildings, vol. 22, no. 1, pp. 50-61, 2013.

[13] P. Fajfar, "Consistent inelastic design spectra: hysteretic and input energy," Earthquake Engineering \& Structural Dynamics, vol. 23, no. 3, pp. 523-537, 1994.

[14] S. K. Kunnath and Y. H. Chai, "Cumulative damage-based inelastic cyclic demand spectrum," Earthquake Engineering \& Structural Dynamics, vol. 33, no. 4, pp. 499-520, 2004.

[15] L. Ye and S. Otani, "Maximum seismic displacement of inelastic systems based on energy concept," Earthquake Engineering \& Structural Dynamics, vol. 28, no. 12, pp. 1483-1499, 1999.

[16] C.-C. Chou and C.-M. Uang, "A procedure for evaluating seismic energy demand of framed structures," Earthquake Engineering \& Structural Dynamics, vol. 32, no. 2, pp. 229-244, 2003.

[17] Y. S. Petryna and W. B. Krätzig, "Compliance-based structural damage measure and its sensitivity to uncertainties," Computers and Structures, vol. 83, no. 14, pp. 1113-1133, 2005.

[18] M. Sugeno, Industrial Applications of Fuzzy Control, Elsevier Science, New York, NY, USA, 1985.

[19] E. Cox, The Fuzzy Systems Handbook, Academic Press, New York, NY, USA, 2nd edition, 1999.

[20] H. Y. Guo, "Structural damage detection using information fusion technique," Mechanical Systems and Signal Processing, vol. 20, no. 5, pp. 1173-1188, 2006.

[21] I. Andreadis, I. Tsiftzis, and A. Elenas, "Intelligent seismic acceleration signal processing for damage classification in buildings," IEEE Transactions on Instrumentation and Measurement, vol. 56, no. 5, pp. 1555-1564, 2007. 
[22] N. Bhushan and K. Ria, Strategic Decision Making: Applying the Analytic Hierarchy Process, Springer, London, UK, 2004.

[23] K. N. Li. CANNY99, Three-Dimensional Nonlinear Dynamic Structural Analysis Computer Program Package, CANNY Consultants PTE, Singapore, 1998. 


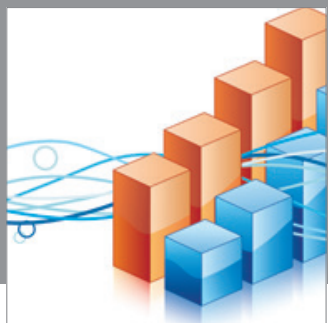

Advances in

Operations Research

mansans

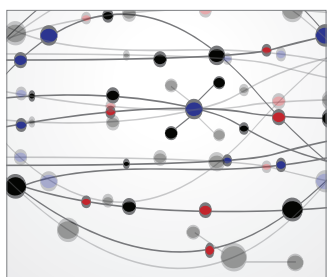

The Scientific World Journal
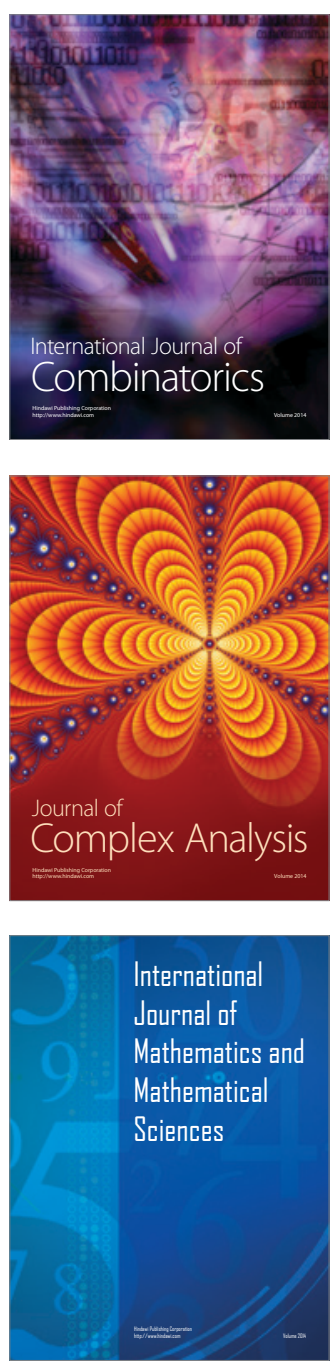
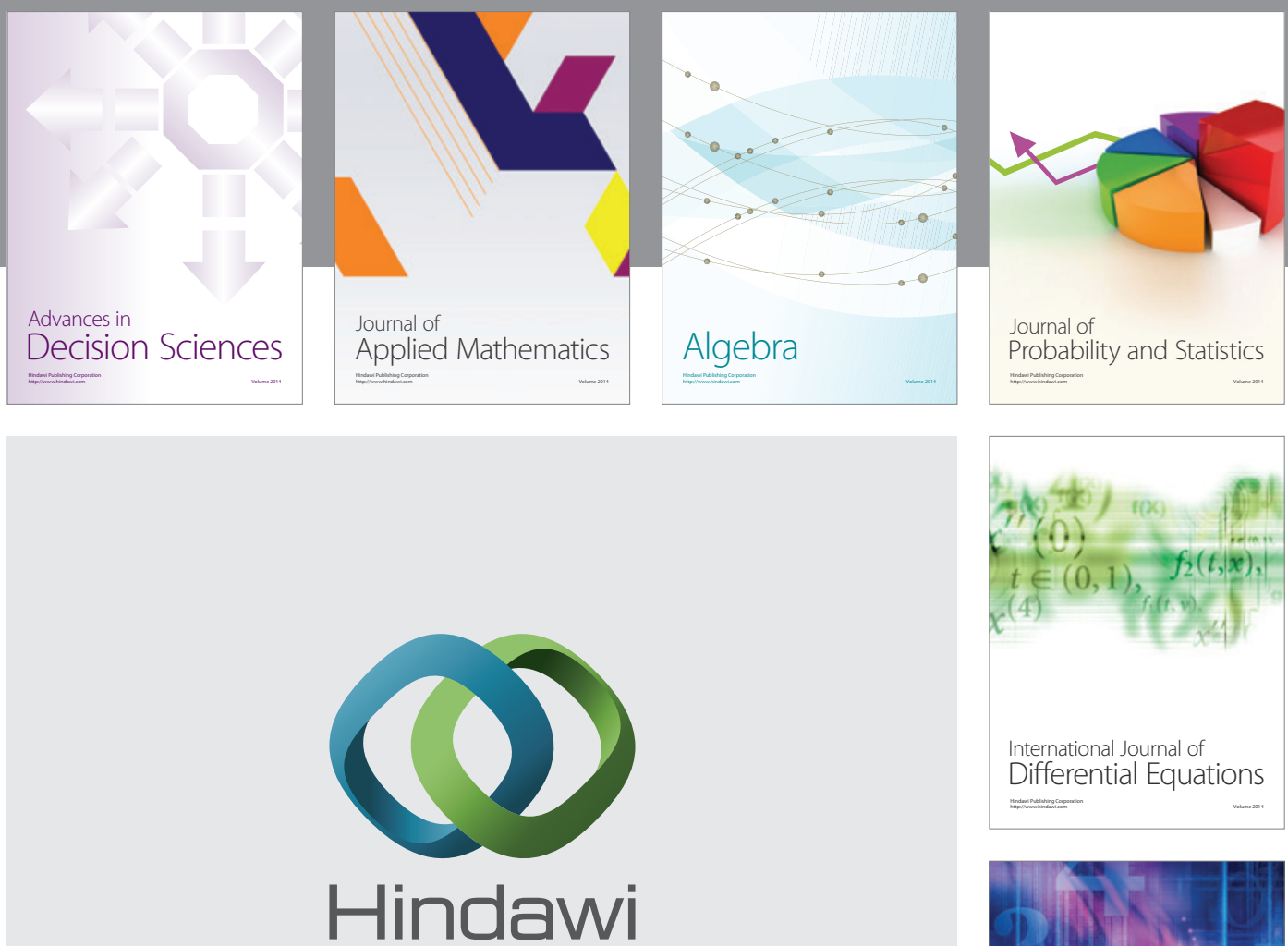

Submit your manuscripts at http://www.hindawi.com
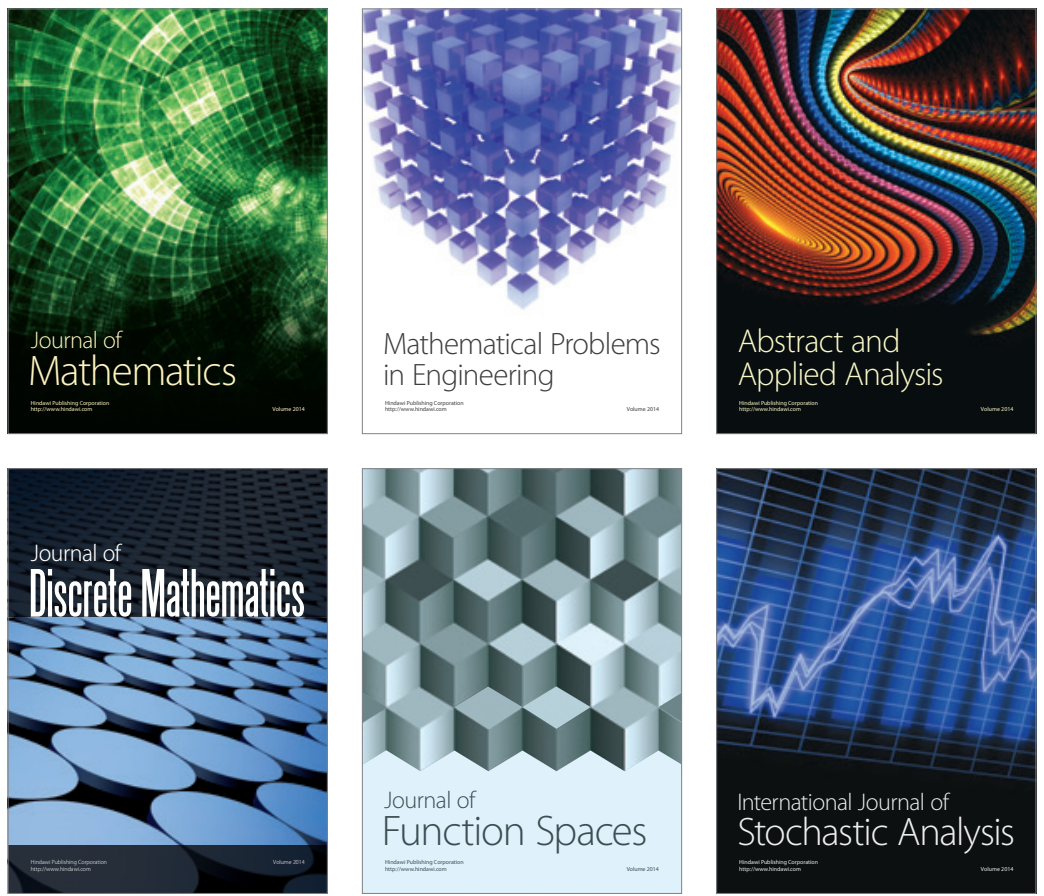

Journal of

Function Spaces

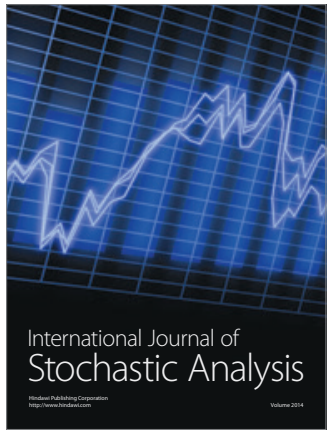

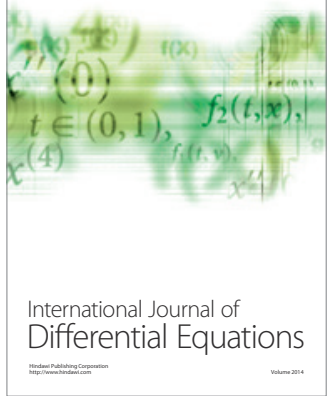
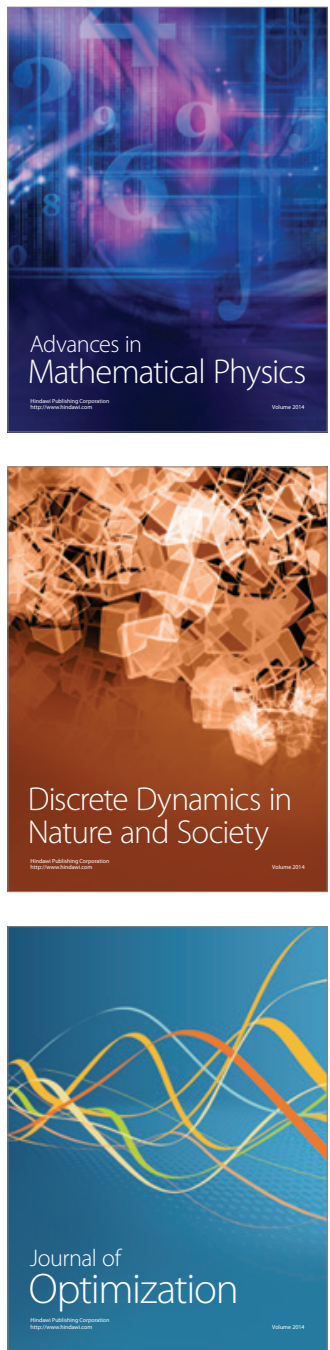